\title{
Guidelines for the use of cannabinoid compounds in chronic pain
}

\author{
AJ Clark MD FRCPC ${ }^{1}$, ME Lynch MD FRCPC ${ }^{2}, M_{\text {Ware MBBS MRCP MSc }}^{3}, \mathrm{P}^{\text {Beaulieu MD PhD FRCA }}{ }^{4}$, \\ I) McGilveray $\mathrm{PhD}^{5}$, D Gourlay MD FRCPC FASAM ${ }^{6}$
}

\begin{abstract}
AJ Clark, ME Lynch, M Ware, P Beaulieu, IJ McGilveray, D Gourlay. Guidelines for the use of cannabinoid compounds in chronic pain. Pain Res Manage 2005;10(Suppl A):44A-46A.

OBJECTIVE: To provide clinicians with guidelines for the use of cannabinoid compounds in the treatment of chronic pain.

METHODS: Publications indexed from 1990 to 2005 in the National Library of Medicine Index Medicus were searched through PubMed. A consensus concerning these guidelines was achieved by the authors through review and discussion.

RESULTS: There are few clinical trials, case reports or case series concerning the use of cannabinoid compounds in the treatment of chronic pain. There are no randomized clinical trials examining the use of herbal cannabis in the treatment of chronic pain.

CONCLUSIONS: A practical approach to the treatment of chronic pain with cannabinoid compounds is presented. Specific suggestions about the off-label dosing of nabilone (Cesamet, Valeant Canada limitée/Limited) and dronabinol (Marinol, Solvay Pharma Inc, Canada) in the treatment of chronic pain are provided.
\end{abstract}

Key Words: Cannabinoid; Chronic pain; Dronabinol; Guideline; Nabilone; Treatment

In Canada, there are presently two synthetic cannabinoids and one cannabis-based medicine available by prescription. The synthetic agents include nabilone (Cesamet, Valeant Canada limitée/Limited) and the synthetic delta-9-tetrahydrocannabinol dronabinol (Marinol, Solvay Pharma Inc, Canada), both of which are available in oral preparations. The cannabis-based medicine (Sativex, GW Pharma Ltd, United Kingdom) is available as a buccal spray and consists of an extract containing delta-9-tetrahydrocannabinol and cannabidiol. Sativex has only recently been approved by Health Canada (as of April 2005) under a conditional notice of compliance.

The approved indication for nabilone and dronabinol is for antiemesis in chemotherapy-induced nausea and vomiting, while the indication listed for the buccal extract is adjunctive treatment for the symptomatic relief of neuropathic pain in multiple sclerosis. Any of these agents prescribed for pain would be considered an 'off-label' use.

In addition, since July 30, 2001, Canadians have had the opportunity to apply for a license to possess herbal cannabis under the Medical Marijuana Access Regulations. Patients may also apply for a license to grow marijuana or may purchase marijuana supplied by Health Canada by completing appropriate forms.

\section{Lignes directrices à l'égard de l'utilisation des substances cannabinoïdes en cas de douleur chronique}

\begin{abstract}
OBJECTIF : Fournir aux cliniciens des lignes directrices à l'égard de l'utilisation des substances cannabinoïdes dans le traitement de la douleur chronique.

MÉTHODOLOGIE : Une recherche a été effectuée dans les publications indexées entre 1990 et 2005 dans la National Library of Medicine Index Medicus par l'entremise de PubMed. Les auteurs sont parvenus à un consensus à l'égard des présentes lignes directrices par suite d'une analyse et de discussions.

RÉSULTATS : Peu d'essais cliniques, de rapports de cas ou de séries de cas portent sur le recours aux substances cannabinoïdes dans le traitement de la douleur chronique. Aucun essai clinique aléatoire ne traite de l'usage du cannabis végétal dans le traitement de la douleur chronique. CONCLUSIONS : Une démarche pratique envers le traitement de la douleur chronique à l'aide de substances cannabinoïdes est présentée. Des suggestions précises sont fournies au sujet du dosage dans une indication non autorisée du nabilone (Cesamet, Valeant Canada limitée/Limited) et du dronabinol (Marinol, Solvay Pharma Inc., Canada) dans le traitement de la douleur chronique.
\end{abstract}

The cannabinoid research field is growing rapidly and there are research programs around the world working on the development of cannabinoids for clinical applications. This includes extracts of naturally occurring agents and the development of novel synthetic cannabinoid agonists and agents that may allow for the modulation of the endogenous cannabinoid system.

As reviewed in the present supplement by Ware and Beaulieu (1) and previously by Campbell et al (2), there are few clinical trials regarding synthetic cannabinoids and there are no randomized clinical trials regarding herbal cannabis in the treatment of chronic pain. In the past three years, several reports have been published about the use of smoked herbal cannabis for the treatment of chronic pain related to various causes including HIV, multiple sclerosis, neuropathic pain and general chronic pain (3-8). These reports have identified that $15 \%$ to $36 \%$ of patients with pain have used, and $10 \%$ to $14 \%$ continue to use, herbal cannabis for symptom relief. Moreover, these reports have provided information about how herbal cannabis is used, including 'doses', route of administration and side effects that were experienced with use. However, this information remains inadequate for the development of guidelines for the use of herbal cannabis. This is also the case with

${ }^{1}$ University of Calgary, Calgary, Alberta; ${ }^{2}$ Dalhousie University, Halifax, Nova Scotia; ${ }^{3}$ McGill University; ${ }^{4}$ Université de Montréal, Montréal,

Québec; ${ }^{5}$ University of Ottawa, Ottawa; ${ }^{6}$ Centre for Addiction and Mental Health, Toronto, Ontario

Correspondence: Dr AJ Clark, Chronic Pain Centre, Calgary Health Region, \#160, 2210 - 2nd Street SW, Calgary, Alberta T2S 3C3.

Telephone 403-943-9900, fax 403-209-2955, e-mail john.clark@calgaryhealthregion.ca 
ased extract and, thus, these guidelines

the buccal cannabis-based extract and, thus, these guidelines
will focus on the two oral cannabinoids currently available by prescription in Canada. For information regarding herbal cannabis under the Medical Marijuana Access Regulations, clinicians are referred to the Health Canada Web site (http://www.hc-sc.gc.ca/hecs-sesc/ocma/).

In general, contraindications to the use of cannabinoids include pregnancy, uncontrolled hypertension, active ischemic heart disease, arrhythmias and schizophrenia. A history of psychosis is a relative contraindication, and because cannabinoids can cause anxiety, they should be used with caution in patients with a past or current anxiety or panic disorder. Moreover, cannabinoids can cause sedation and cognitive effects. Thus, the usual cautions given for opioids, benzodiazepines or any potentially sedating agent are applicable. Patients should be cautioned not to drive or to operate heavy machinery, etc, if experiencing any side effects that would impair their performance in these activities. Patients with comorbid depression and other psychiatric disorders should be carefully monitored. Cannabinoids should be administered initially at low doses and titrated slowly to balance positive and negative acute effects. Patients should be advised of the likelihood and nature of acute effects, and close monitoring is advised during initial dose titration.

\section{EVALUATING A PATIENT FOR A TRIAL OF A CANNABINOID}

Prudent medical practice incorporates a comprehensive evaluation of a patient when new therapies are considered. The following suggestions are similar to those endorsed by the Canadian Pain Society in its consensus statement and guidelines for the use of opioid analgesics in the treatment of noncancer pain (9):

- perform a history and examination;

- assess the level of pain;

- assess psychological contributors and risk of addiction or substance abuse;

- document any history or current use of illicit or nonprescribed drugs, including cannabis and synthetic cannabinoids;

- determine the effect of the previous use of cannabinoids on pain;

- consider urine drug screening to assess the current use of prescribed and nonprescribed medications;

- set goals of treatment with a cannabinoid - consider reduction of pain, increased functional abilities, improved sleep quality, increased quality of life and a reduction in the use of other medications;

- develop a treatment plan incorporating these goals;

- discuss possible side effects that may be experienced with use (eg, central nervous system, cardiovascular and respiratory);

- discuss the risks of addiction;

- develop a follow-up schedule to periodically review the patient (the five As - Analgesia, Activities, Adverse events, Abuse behaviours and Adequate documentation);

- determine whether the goals of treatment are being achieved and the appropriateness of response; and
- Full assessment, establish diagnosis of pain

- Assess psychosocial issues and risk of addiction

- Determine history of previous use of illicit substances or misuse of prescription drugs

- Develop a treatment plan assuring that pharmacotherapy takes place within an overall active participatory approach

- Ensure that traditional approaches to chronic pain management have been tried or considered

- Consider cautions and ensure no contraindications to use of cannabinoid

- Discuss potential adverse effects

- Consider discussing urine testing

- Review and sign treatment agreement

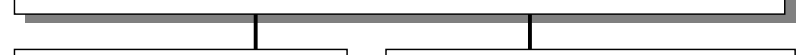

Cannabinoid-naïve:

- Start an oral cannabinoid available by prescription*

\begin{tabular}{|l|}
\hline *NCesamet ${ }^{\circledR}$ (synthetic \\
analogue of $\mathrm{THC}$, \\
nabilone) or $\mathrm{NMarinol}$ \\
(synthetic $\mathrm{THC}$, \\
dronabinol)
\end{tabular}

- Previous use of cannabinoids: cannabinoid use

- Specific cannabinoid, dose, route of administration

- Symptoms treated and outcome - Adverse effects

- Encourage oral route of administration and initiate trial of oral cannabinoid available by prescription*
If oral nabilone or dronabinol trial fails or is not financially feasible, consider cannabis:

- Discuss the fact that there are not yet clear guidelines regarding efficacy,

- doses and toxicity

- Raise awareness of oral and vaporized routes of administration

- Refer patient to Health Canada Web site and documents regarding cannabis product

- Follow the usual clinical guidelines to start low and titrate dose slowly

Figure 1) Algorithm for the treatment of chronic pain with cannabinoids

- consider developing a treatment agreement with the patient, particularly if he/she is at risk.

Documentation is essential to demonstrate the evaluation of the patient, the rationale for the use of a cannabinoid in the context of the overall management plan and the periodic review of the patient's status.

An algorithm for the treatment of chronic pain is provided in Figure 1.

Common side effects associated with the use of the cannabinoids are detailed in Table 1.

\section{Risk of addiction to and abuse of Cesamet, Marinol and Sativex}

Marinol is available suspended in sesame oil in capsule form in $2.5 \mathrm{mg}, 5 \mathrm{mg}$ and $10 \mathrm{mg}$ strengths. Cesamet is available as a pulvule (powder-containing capsule) in $0.5 \mathrm{mg}$ and $1 \mathrm{mg}$ strengths. Sativex is available as a buccal spray. As Gourlay (10) notes in the present supplement, it has been previously reported that the abuse liability of Marinol is low because the drug lacks the desirable qualities of rapid onset and titratability commonly seen in drugs of abuse. The same is true for Cesamet due to its compounding as a pulvule; it too does not appear to lead to misuse or abuse. Comparisons of the reinforcing properties of oral tetrahydrocannabinol, smoked cannabis and nabilone in subjects with previous cannabis experience indicate that smoked cannabis was significantly more reinforcing than all other cannabis compounds studied, regardless of 
TABLE 1

Common and important side effects of cannabinoids

\begin{tabular}{ll}
\hline Central nervous & Euphoria \\
system & Anxiety \\
& Panic \\
& Paranoia \\
& Psychosis \\
& Sedation \\
& Dizziness \\
& Somnolence \\
& Depression \\
& Ataxia \\
& Possible visual/hearing disturbances \\
& Asthenia \\
& Possible cognitive effects \\
& Tachycardia \\
& Postural hypotension \\
& Palpitations \\
& Vasodilation (flushing, red eyes) \\
Increased risk of myocardial infarction within & 1 h of use \\
Rardiovascular & Bronchitis/chronic obstructive pulmonary disease \\
& Lung infection \\
Increased risk for upper airway cancer & Dry mouth \\
& Headache \\
& Abdominal pain/bloating \\
\hline &
\end{tabular}

drug-use history (10). We do not currently have adequate information concerning Sativex and abuse liability.

\section{Guidelines for the use of Cesamet}

Cesamet has been available in Canada since 1981 and is indicated for use as an antiemetic and to treat anorexia associated with AIDS. There have been no adequate randomized clinical trials on the use of Cesamet in chronic pain, although there are two clinical reports $(11,12)$ showing a modest benefit in some patients.

When other therapies have failed to provide adequate pain relief or have caused unacceptable side effects, it is reasonable to consider a trial of an oral cannabinoid:

- initiate Cesamet at $0.5 \mathrm{mg}$ orally at night time; and

- increase dose by $0.5 \mathrm{mg}$ every two to three days to a maximum dose of $2 \mathrm{mg}$ orally twice daily.

Guidelines for the use of Marinol

Marinol is indicated for use as an antiemetic. There is one randomized clinical trial (13) of Marinol (with a dose up to $10 \mathrm{mg}$ ) showing a modest effect in the treatment of central pain in patients with multiple sclerosis. An 'N-of-1' trial in noncancer pain subjects has demonstrated improvement in pain similar to that with codeine at doses of $10 \mathrm{mg}$ or higher (14).

\section{P INC, = DO NOT COPY}

When other therapies have failed to provide adequate pain relief or have caused unacceptable side effects, it is reasonable to consider a trial of an oral cannabinoid:

- initiate Marinol at $2.5 \mathrm{mg}$ orally at night time; and

- increase dose by $2.5 \mathrm{mg}$ every two to three days to a maximum dose of $10 \mathrm{mg}$ twice daily orally.

\section{Sativex}

Sativex is only approved for use as an adjunctive treatment for the symptomatic relief of neuropathic pain in multiple sclerosis. The product monograph for Sativex recommends a "gradual increase in dose as needed and tolerated until satisfactory pain relief is achieved" (15). There is insufficient published information on the dosing of Sativex to make recommendations about its use at this time.

\section{REFERENCES}

1. Ware M, Beaulieu P. Cannabinoids for the treatment of pain: An update on recent clinical trials. Pain Res Manage 2005;10(Suppl A):27A-30A.

2. Campbell FA, Tramer MR, Carroll D, Reynolds DJ, Moore RA, McQuay HJ. Are cannabinoids an effective and safe treatment option in the management of pain? A qualitative systematic review. BMJ 2001;323:13-6.

3. Lynch ME, Clark AJ. Cannabis reduces opioid dose in the treatment of chronic non-cancer pain. J Pain Symptom Manage 2003;25:496-8

4. Ware M, Gamsa A, Persson J, Fitzcharles M. Cannabis for chronic pain: Case series and implications for clinicians. Pain Res Manag 2002;7:95-9.

5. Ware MA, Doyle CR, Woods R, Lynch ME, Clark AJ. Cannabis use for chronic non-cancer pain: Results of a prospective survey. Pain 2003;102:211-6.

6. Page SA, Verhoef MJ, Stebbins RA, Metz LM, Levy JC. Cannabis use as described by people with multiple sclerosis. Can J Neurol Sci 2003;30:201-5

7. Clark AJ, Ware MA, Yazer E, Murray TJ, Lynch ME. Patterns of cannabis use among patients with multiple sclerosis. Neurology 2004;62:2098-100

8. Prentiss D, Power R, Balmas G, Tzuang G, Israelski DM. Pattern of marijuana use among patients with HIV/AIDS followed in a public health care setting. J Acquir Immune Defic Syndr 2004:35:38-45.

9. Jovey RD, Ennis J, Gardner-Nix J, et al; Canadian Pain Society. Use of opioid analgesics for the treatment of chronic noncancer pain consensus statement and guidelines from the Canadian Pain Society, 2002. Pain Res Manage 2003;8(Suppl A):3A-28A.

10. Gourlay D. Addiction and pain medicine. Pain Res Manag 2005;10(Suppl A):38A-43A.

11. Notcutt WG, Price M, Chapman G. Clinical experience with nabilone for chronic pain. Pharm Sci 1997;3:551-5.

12. Martyn CN, Illis LS, Thom J. Nabilone in the treatment of multiple sclerosis. Lancet 1995;345:579.

13. Svendsen KB, Jensen TS, Bach FW. Does the cannabinoid dronabinol reduce central pain in multiple sclerosis? Randomised double blind placebo controlled crossover trial. BMJ 2004:329:253.

14. Naef M, Curatolo M, Petersen-Felix S, Arendt-Nielsen L, Zbinden A Brenneisen R. The analgesic effect of oral delta-9. tetrahydrocannabinol (THC), morphine, and a THC-morphine combination in healthy subjects under experimental pain conditions. Pain 2003;105:79-88.

15. Sativex product monograph. GW Pharmaceuticals. Salisbury: United Kingdom, 2005. 


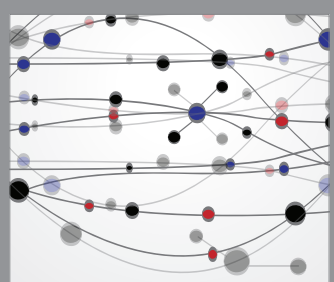

The Scientific World Journal
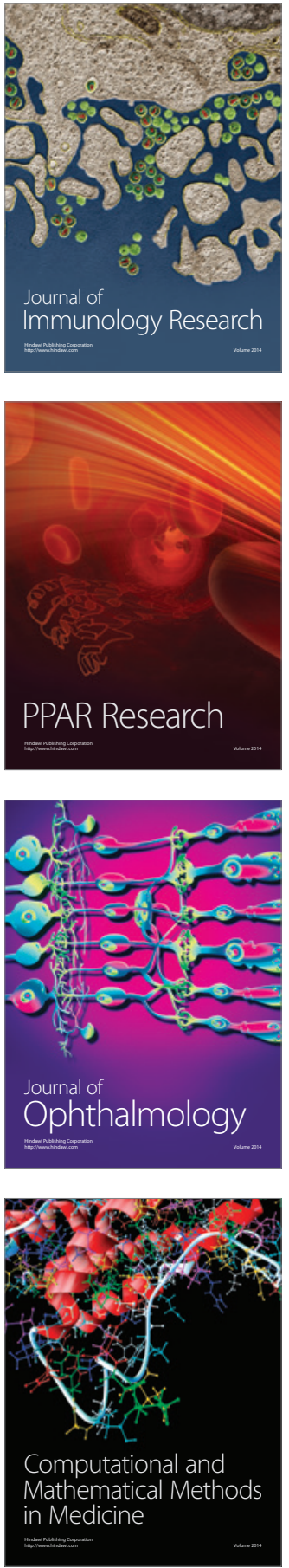

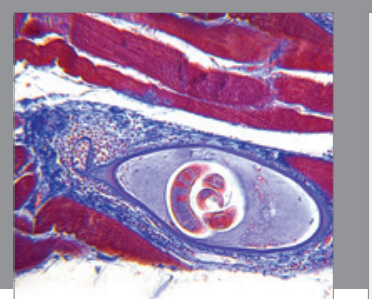

Gastroenterology Research and Practice

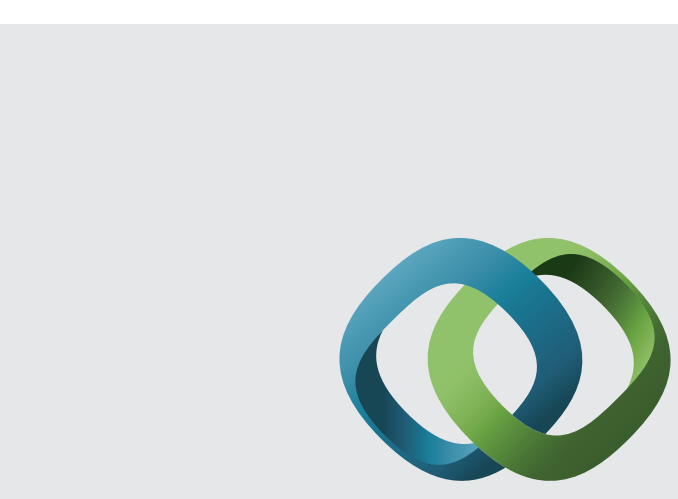

\section{Hindawi}

Submit your manuscripts at

http://www.hindawi.com
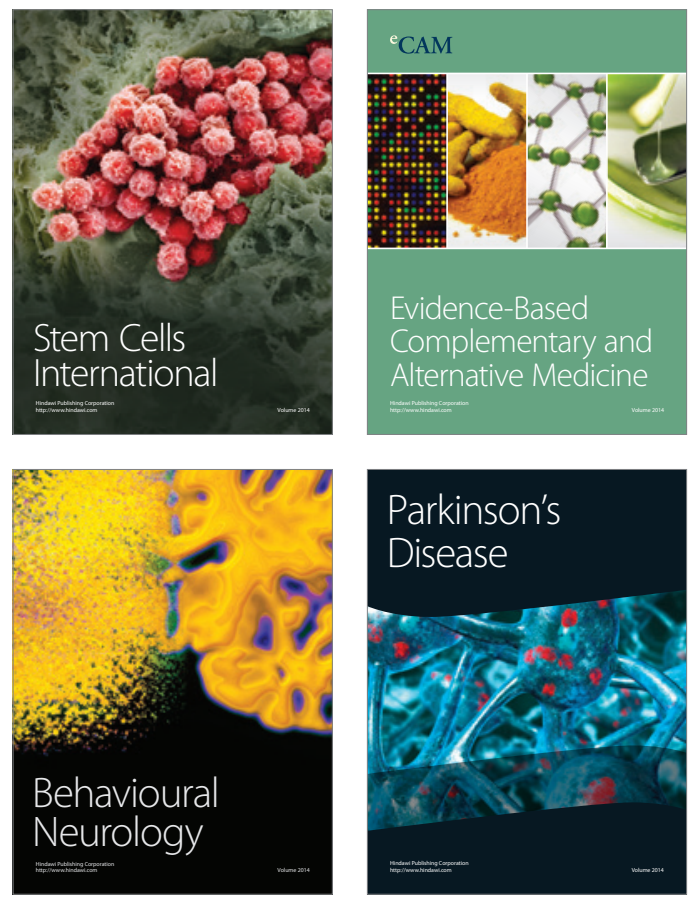
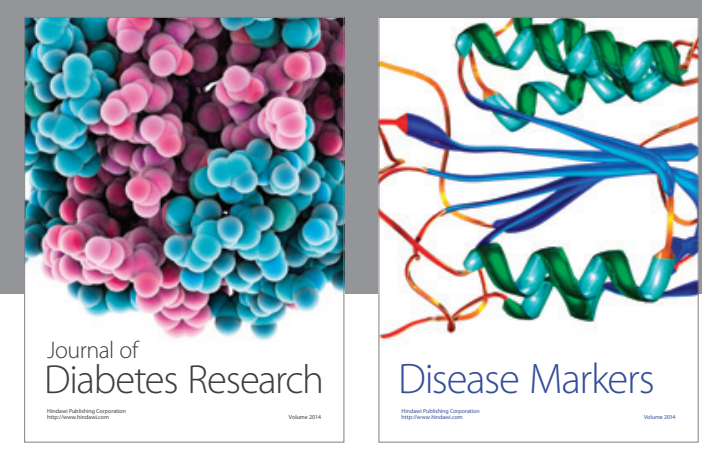

Disease Markers
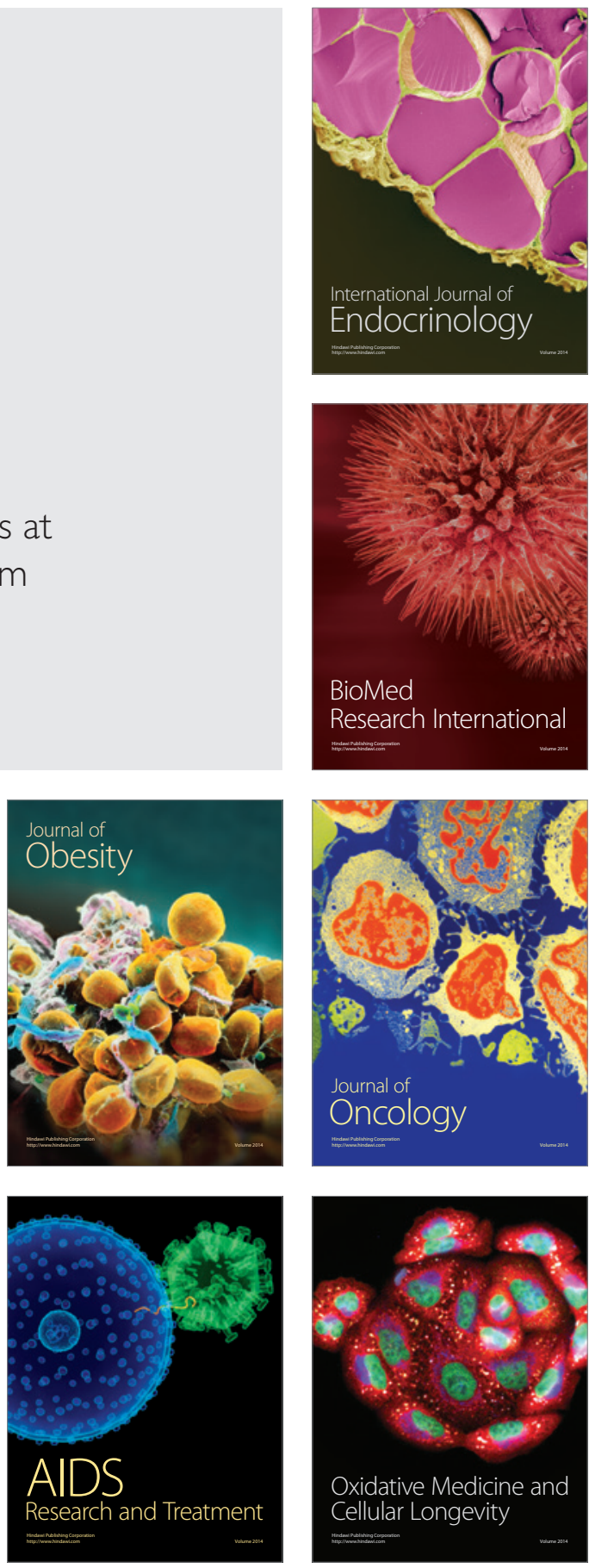